\title{
BMJ Open Assessing potentially inappropriate prescribing (PIP) and predicting patient outcomes in Ontario's older population: a population-based cohort study applying subsets of the STOPP/START and Beers' criteria in large health administrative databases
}

\author{
Lise M Bjerre, ${ }^{1,2,3,4}$ Timothy Ramsay, ${ }^{4,5}$ Catriona Cahir, ${ }^{6}$ Cristín Ryan, ${ }^{7}$ \\ Roland Halil, ${ }^{1}$ Barbara Farrell, ${ }^{1,2,8}$ Kednapa Thavorn, ${ }^{3,4,5}$ Christina Catley, ${ }^{3}$ \\ Steven Hawken, ${ }^{3,4,5}$ Ulrika Gillespie, ${ }^{9}$ Douglas G Manuel ${ }^{1,2,3,4,5}$
}

To cite: Bjerre LM,

Ramsay T, Cahir C, et al. Assessing potentially inappropriate prescribing (PIP) and predicting patient outcomes in Ontario's older population: a populationbased cohort study applying subsets of the STOPP/START and Beers' criteria in large health administrative databases. BMJ Open 2015;5:e010146. doi:10.1136/bmjopen-2015010146

- Prepublication history and additional material is available. To view please visit the journal (http://dx.doi.org/ 10.1136/bmjopen-2015010146).

Received 2 October 2015 Accepted 20 October 2015

CrossMark

For numbered affiliations see end of article.

Correspondence to Dr Lise M Bjerre; lbjerre@bruyere.org

\section{ABSTRACT}

Introduction: Adverse drug events (ADEs) are common in older people and contribute significantly to emergency department (ED) visits, unplanned hospitalisations, healthcare costs, morbidity and mortality. Many ADEs are avoidable if attention is directed towards identifying and preventing inappropriate drug use and undesirable drug combinations. Tools exist to identify potentially inappropriate prescribing (PIP) in clinical settings, but they are underused. Applying PIP assessment tools to population-wide health administrative data could provide an opportunity to assess the impact of PIP on individual patients as well as on the healthcare system. This would open new possibilities for interventions to monitor and optimise medication management on a broader, population-level scale.

Methods and analysis: The aim of this study is to describe the occurrence of PIP in Ontario's older population (aged 65 years and older), and to assess the health outcomes and health system costs associated with PIP-more specifically, the association between PIP and the occurrence of ED visits, hospitalisations and death, and their related costs. This will be done within the framework of a populationbased retrospective cohort study using Ontario's large health administrative and population databases. Eligible patients aged 66 years and older who were issued at least 1 prescription between 1 April 2003 and 31 March 2014 (approximately 2 million patients) will be included.

Ethics and dissemination: Ethical approval was obtained from the Ottawa Health Services Network Ethical Review Board and from the Bruyère Research Institute Ethics Review Board. Dissemination will occur via publication, presentation at national and international conferences, and ongoing exchanges with regional, provincial and national stakeholders, including
Strengths and limitations of this study

- The application of medication appropriateness criteria (such as the STOPP/START and Beers' criteria) to health administrative data provides a unique opportunity to estimate the prevalence of potentially inappropriate prescribing (PIP) at the population level, with near-complete coverage (our study population will comprise approximately $97 \%$ of Ontario's seniors) and to assess its impact, both human and economic, at the individual and societal level.

- This study is expected to identify patient and prescriber characteristics associated with a higher likelihood of PIP, which could become the target of interventions aimed at improving the quality of prescribing.

- The use of health administrative data provides high power to detect relevant associations at comparatively lower cost than would be possible using clinical data collected at the bedside.

- Several limitations may be encountered that are inherent to studies relying on health administrative data, including uncertainty surrounding patient adherence to dispensed medications, the unavailability of some clinical or diagnostic data, and the absence of data for over-the-counter or non-formulary medications. Each of these could impact the estimate of true PIP in the population.

- Adverse effects of medication are known to be broadly under-recognised and under-reported, particularly in health administrative data, which may limit this study's ability to detect medication-specific patient outcomes; for this reason, more reliable outcome measures, such as the occurrence of emergency department visits, hospitalisation and mortality, will be used as main outcomes for this study. 
the Ontario Drug Policy Research Network and the Ontario Ministry of Health and Long-Term Care.

Trial registration number: Registered with clinicaltrials.gov (registration number: NCT02555891).

\section{INTRODUCTION}

\section{Background}

Older people consume a disproportionate share of medication compared with younger people. According to a recent report from the Canadian Institute for Health Information (CIHI) released in May 2014, patients aged 65 years and older currently represent $15 \%$ of the Canadian population, yet their spending on prescription medications accounts for over $40 \%$ of all retail prescription drug sales and $60 \%$ of public drug programme spending, ${ }^{1}$ three times the Canadian average. Furthermore, nearly two-thirds $(65.9 \%)$ of Canadian patients aged 65 years and over had claims for 5 or more drug classes, and more than one-quarter $(27.2 \%)$ of seniors had claims for 10 or more drug classes. $^{2}$ Finally, older people are at higher risk of adverse drug events (ADEs) than the rest of the population. ${ }^{3} 4$ This elevated risk of ADE is due to various factors, including higher numbers of medications prescribed per person, increasing numbers of prescribers, greater sensitivity to medication effects secondary to natural age-related and disease-related changes in pharmacokinetics, as well as higher baseline risk of disease including higher likelihood of multimorbidity. ${ }^{3} 4$

The occurrence of ADE contribute significantly to more frequent emergency department (ED) visits, unplanned hospitalisations, ${ }^{5}$ high healthcare costs, ${ }^{6}$ morbidity and mortality in older populations. ${ }^{7}$ A recent study showed that, of 600 older patients admitted to hospital for an acute illness, $25 \%$ of them had one or more ADEs prior to hospitalisation, of which two-thirds had contributed to the hospitalisations. ${ }^{8}$ Of these events, $69 \%$ were deemed avoidable.

Potentially inappropriate prescribing (PIP), which includes errors of co-mission as well as of omission, is common in older people. Its likelihood increases with the number of medications prescribed and it is often associated with increased costs. ${ }^{9-11}$ A number of medication assessment tools exist to identify PIP that can lead to ADE. ${ }^{9-19}$ Unfortunately, few of these tools have been shown to reliably predict ADE, ${ }^{17}$ and although there are a few studies showing associations between PIP and adverse outcomes, their predictive validity needs to be assessed further, particularly using large-scale national health databases.

\section{STOPP/START criteria}

The STOPP/START criteria $^{20} 21$ were developed by a multidisciplinary team of geriatricians, pharmacists, pharmacologists and primary care physicians and consist, in the updated 2014 version, of 81 STOPP and
34 START criteria organised by physiological organ system; STOPP criteria target errors of commission, whereas START are concerned with errors of omission.

STOPP lists instances of PIP that should be avoided, drug interactions and drugs that increase risk of falls, while START lists instances of potential prescribing omissions, where clinically indicated medicines are not prescribed. The STOPP/START criteria were successfully applied, with good inter-rater reliability, in a number of settings, revealing rates of PIP of $22 \%$ in primary care clinics, $35 \%$ in acute hospital settings and $60 \%$ in nursing homes. ${ }^{12} 162022$ In a validation study, screening medications with the STOPP/START criteria was associated with the subsequent use of fewer medications, fewer incorrect doses and lower potential interactions. ${ }^{23}$

\section{Beers' criteria}

The Beers' criteria were the first explicit criteria to be published and have become widely used, particularly in the USA where they originated. ${ }^{1724}$ These criteria were originally developed for use in nursing home patients; they were modified three times, in $1997,,^{25} 2003^{15}$ and $2012,{ }^{26}$ and are now intended for use in all patients above 65 years of age. Despite their popularity, the Beers' criteria have been criticised for including obsolete medications, as well as medications no longer available outside the USA, particularly in Europe,${ }^{8}{ }^{10}$ though some of these issues have been addressed in the 2012 revision. ${ }^{26-29}$ They have also been criticised for not being sufficiently inclusive of a number of common instances of PIP. ${ }^{8}{ }^{17}$ In particular, Beers only lists drugs to avoid, but does not include other categories of PIP, such as drug-drug and drug-disease interactions, drug duplications or underuse and overuse of medications. ${ }^{17}$ Finally, Beers' criteria have not been shown to be associated with experiencing an ADE, discharge to a higher level of care or in-hospital mortality. ${ }^{30}$

In a review of medication review tools performed before the 2012 Beers' update and the 2014 STOPP/ START update, STOPP/START were deemed 'most promising', and were thought to have international applicability. ${ }^{31}$

\section{Assessing PIP at the population level}

There are relatively few studies looking at the appropriateness of prescribing at the population level. However, population-level approaches using health administrative data have the potential to assess the impact of inappropriate prescribing on large numbers of individual patients as well as on healthcare systems. ${ }^{9}$

STOPP/START criteria were designed for use in conjunction with patients' clinical records; therefore, access to patients' full medical records and biochemical (laboratory) data are necessary in order to deploy the full set of criteria. As this information is usually not available in health administrative databases, a subset of STOPP criteria (26 out of the 65 original STOPP criteria) that did not require patient-level clinical data were 
identified by Cahir et $a l^{9}$ START criteria could not be used because they all require clinical data. The subset of STOPP criteria was applied to population-level health administrative prescription data to identify instances of PIP, and to estimate their cost. ${ }^{9}$ The authors concluded that the total healthcare expenditures on PIP amounted to $9 \%$ of the overall drug expenditures of Ireland. ${ }^{9}$ They were not able to assess the association of inappropriate prescribing with patient outcomes (ED visits, hospitalisations or mortality) and their associated costs, as these data were not available in their database.

Ontario possesses a comprehensive collection of linked health administrative databases containing drug, health services, socioeconomic and patients' health outcome data such as ED visits, hospitalisations and deaths. These data sets offer opportunities to prospectively assess the frequency of PIP, as well as associated outcomes and costs for a whole population. In the present study, we will apply a subset of the 2014 STOPP, START ${ }^{21}$ and 2012 Beers' criteria ${ }^{26}$ to Ontario's population-wide health administrative data to describe the occurrence of PIP in Ontario's older population, and assess the health outcomes and health system costs associated with it.

\section{Evidence gaps to be filled}

Using subsets of STOPP/START and, possibly, Beers' criteria applicable to health administrative data is a promising approach for the identification of PIP in older patients. Nonetheless, although PIP identified using STOPP/START criteria have been shown to be associated with ADEs and hospitalisations in clinical cohort studies, ${ }^{8} 32 \quad 33$ a number of questions remain unanswered, particularly with respect to their application to population-wide health administrative data. In this context, it remains to be established whether a subset of STOPP/START and/or Beers' criteria are predictive of relevant patient outcomes, such as the incidence of ADE, ED visits, hospitalisations, composite healthcare utilisation and mortality. Furthermore, it is not clear whether such a subset of criteria could help identify patient and prescriber characteristics associated with a high likelihood of PIP, which could become the target of interventions aimed at improving the quality of prescribing.

To address these knowledge gaps, we will test three hypotheses pertaining to the effects of PIP on Canada's senior population:

1. Instances of PIP are frequent and costly.

2. ED visits and hospitalisations are significantly associated with PIP.

3. The likelihood of PIP is associated with patient and physician characteristics.

Identifying significant associations for some or all of the aforementioned hypotheses could provide evidence to support important policy measures aimed at effectively reducing PIP and its consequences on patients and the healthcare system on a broader, population-level scale.
METHODS AND ANALYSIS

\section{Study design}

We will conduct a population-based, retrospective, dynamic (open) cohort study.

\section{Definition of observation periods}

The study period will span from 1 April 2002 to 31 March 2014. These dates were chosen based on availability for all the required databases at the projected time of study initiation (fall 2015); should recent data be available at the time the study is conducted, the end of the study period will be adjusted to allow inclusion of these data. The accrual period is defined at the period for ascertainment of exposure (the occurrence of PIP); it starts 1 year after the start of the study period (ie, on 1 April 2003), and ends 1 year before the end of the study period (ie, on 31 March 2013). This will allow a 1-year look-back period preceding the first included PIP, to describe prior health services utilisation, medication use and comorbidities (baseline risks), as well as a 1-year follow-up period after the last possible PIP, to allow for adequate follow-up of patient outcomes (see figure 1 for a graphical illustration of study period, accrual period and time frame for ascertainment of baseline risks, exposures and outcomes).

\section{Participants \\ Inclusion/exclusion criteria}

Individuals eligible for participation in the study will include all patients who were: (1) continuously eligible for Ontario Health Insurance Plan (OHIP) coverage, (2) issued at least one prescription (of any type) during the accrual period (between 1 April 2003 and 31 March 2013), and (3) 66 years of age or older at the date of first dispensation during the accrual period; this is necessary to ensure the availability of 1 year of background information on medication and health services use for all patients. Instances of PIP will be identified and catalogued during the accrual period.

The index date of a patient's recruitment into the study cohort will be the date of the first prescription dispensed following the beginning of the accrual period (1 April 2003). Patients will be excluded if they do not have a valid OHIP number. This includes individuals whose healthcare is provided by other plans (eg, First Nations people living on reserves, members of the Canadian Armed Forces and refugee claimants) and is therefore not captured by Institute for Clinical Evaluative Sciences (ICES) data. Patients will also be excluded if they were not OHIP-eligible for at least 1 year prior to the index date, or 1 year after the index date, or if they do not have continuous OHIP coverage between these two dates; this is necessary to ensure that predictors and outcomes of PIP can be adequately captured. Patients not dispensed any prescription medication will not be included in the study. The selection of the study cohort is shown graphically in figure 2. Based on these criteria, we estimate that in excess of two 
Figure 1 Definition of observation period (OHIP, Ontario Health Insurance Plan).

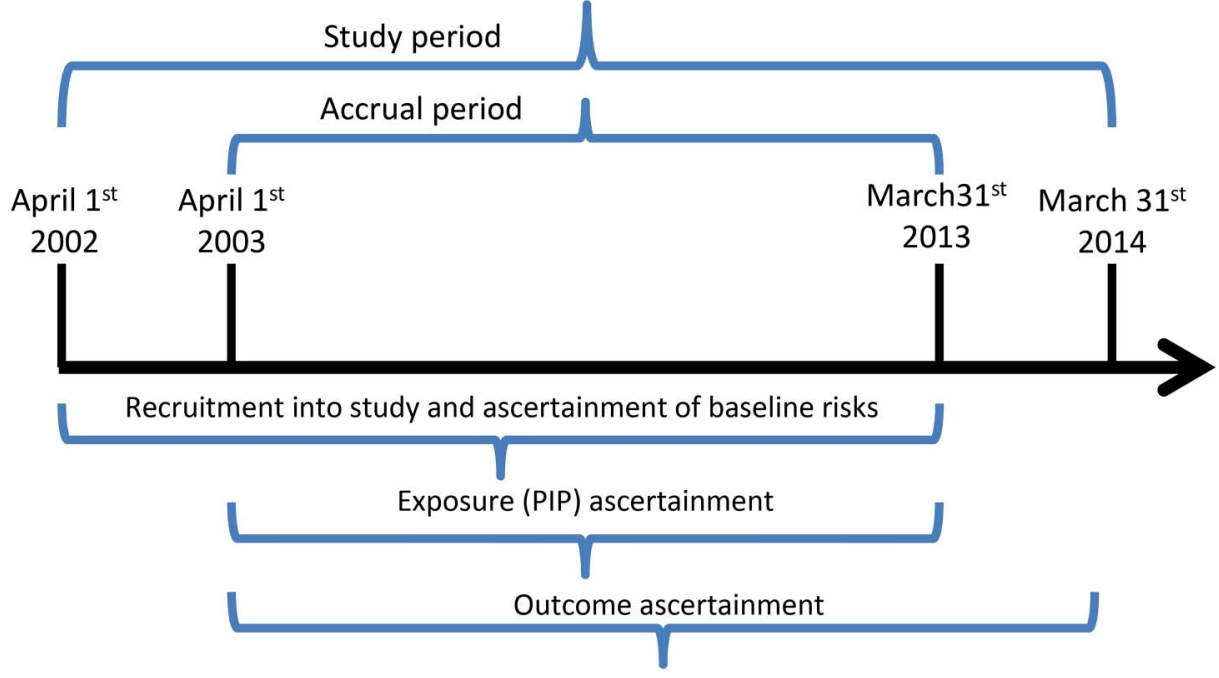

All OHIP-eligible adults

between April 1st, 2002 and March 31st, 2014

(study period) $(\mathrm{n}=)$

EXCLUSIONS

Patients without OHIP coverage during this study period $(n=)$

Patients issued at least one prescription (of any type) between April 1st, 2003 and March 31st, 2013 (accrual period) $(n=)$

(Date of first prescription is the INDEX DATE)

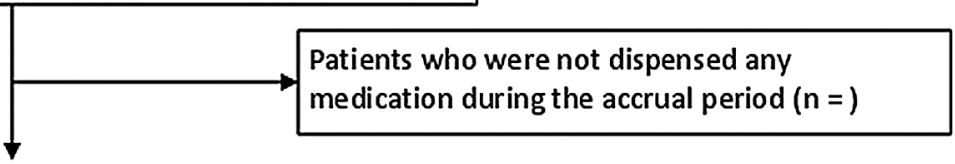

Patients who were 66 yrs or older at the date of first dispensation $(n=)$

Patients who were not 66 yrs or older at the date of first dispensation $(n=)$

Patients who were not OHIP-eligible for one year after their index date $(n=)$

Patients who were not OHIP-eligible for one year prior to their index date $(n=)$

Patients who died before their index

dispensation $(n=)$

Final Cohort $(\mathrm{n}=)$

Figure 2 Description of study cohort creation (PIP, potentially inappropriate prescribing). 
million patients will contribute data to our study (see Methods section, 'Validation and power', for calculations leading to this estimate).

\section{Data sets}

Patient data will be drawn from linked and de-identified health administrative data sets housed at the ICES, which will be accessed from the ICES@uOttawa site. ICES is an independent, non-profit organisation funded by the Canadian province of Ontario's Ministry of Health and Long-Term Care (MOHLTC). ICES databases contain information on hospital and outpatient use of health services, demographic data and socioeconomic data for over 13 million Ontarians. All of these data sets are linked using a patient-specific encrypted identifier. This study will use five general use health services data sets. ${ }^{34} 35$

\section{Ontario Drug Benefits Claims Database}

The Ontario Drug Benefit (ODB) programme provides drug benefits for all Ontario residents aged 65 and older and those with disability/social assistance benefits. The Ontario Drug Benefits Claims Database (ODBD) contains a number of data related to prescription drugs, including drug identification number (DIN), quantity of drugs provided, number of days supplied (which can be used to compute the daily dose), itemised cost, dispensing fee, long-term care indicators, the plan affiliated with the prescription (eg, Seniors, Trillium, Ontario Works, etc), the date the drug was dispensed, and patient and prescriber identifiers (encrypted). Additionally, ICES maintains a list linking DINs to their associated drug and product names, subclass information, pharmacological-therapeutic classification group codes, drug strength, route of administration, and first and last dispensing dates from the ODB. ${ }^{35}$

\section{Discharge Abstract Database}

The Discharge Abstract Database (DAD) captures all acute care hospitalisations in Ontario dating back to 1988. Each row in the DAD records demographic, diagnostic, procedural and treatment information for a given hospitalisation. ${ }^{35}$

\section{Same Day Surgery Database}

The Same Day Surgery Database (SDS) contains patientlevel data for day surgery institutions in Ontario. Every record corresponds to one same-day surgery or procedure stay.

\section{National Ambulatory Care Reporting System}

The National Ambulatory Care Reporting System (NACRS) captures all visits to hospital EDs beginning in 2002. As with the DAD, each row of the NACRS contains demographic, diagnostic, procedural and treatment information for each emergency room visit. ${ }^{35}$

\section{OHIP database}

The OHIP database captures health services billing claims paid by the OHIP to providers. Each row in the OHIP database records the patient, provider and diagnosis/procedure being claimed for remuneration.

Care provider data will be obtained from the ICES Physician Database (IPDP), which contains yearly information about all physicians in Ontario, including physician demographics (age, sex); specialty (functional and certified); location; and measures of physician activity (billings, workload, types or services provided). The Client Agency Program Enrolment (CAPE) database will be used to determine the enrolment of an individual in a programme with a specific practitioner and group. Birth date and death date of every individual eligible for Ontario health service will be obtained from the Registered Persons Database (RPDB). ${ }^{35}$ In addition, we will utilise five ICES-derived cohorts for case ascertainment of diseases specified in the STOPP/START and Beers' criteria: asthma, diabetes, hypertension, chronic obstructive pulmonary disease and congestive heart failure.

\section{Exposure and outcomes}

An overview of all variable definitions and units is presented in table form (table 1) and the variables are expanded on in the following paragraphs.

\section{Exposure variable}

The main exposure variable will be the occurrence of the first PIP ever during the accrual period (see figure 3). This will be used to quantify the association of a first PIP with an outcome (see 'Primary outcome' below).

A secondary exposure variable will be defined to assess the overall impact of PIP burden on patient outcomes: we define this secondary outcome as the annualised number of first PIPs for any STOPP/START or Beers' criterion experienced by each patient during his or her accrual period, a quantity which we term the 'first (criterion-specific) PIP incidence density'. PIP incidence density will be calculated separately for STOPP/START and for Beers' criteria. Since different patients will have different accrual periods, this variable will be expressed on an annualised basis, where the numerator is the total number of first criterion-specific PIPs experienced by the patient, and the denominator is the person-time contributed by the patient during his or her accrual period. Since patients can only experience one first PIP per criterion, subsequent PIPs for the same criterion will not be considered. This approach is made necessary because the risk of outcome is likely to change with habituation and prolonged exposure to a given PIP, and to reduce the impact of patients with a large number of PIPs for a given medication, or combination of medications.

To identify PIP, we will apply a subset of STOPP/ START and Beers' criteria applicable to health administrative data by assessing both the patient's drug history, as recorded in the ODBD, and disease history as obtained from linking DAD, SDS, NACRS, OHIP and 
Table 1 Variable definitions and units

\begin{tabular}{|c|c|c|c|c|c|}
\hline Category & Variable name & Definition & Scale & Valid range/levels & Units \\
\hline $\begin{array}{l}\text { Main } \\
\text { exposure } \\
\text { variable }\end{array}$ & First PIP ever & $\begin{array}{l}\text { Occurrence of the first PIP ever } \\
\text { experienced by a patient during } \\
\text { his/her study eligibility period }\end{array}$ & Dichotomous & Yes or no & $\begin{array}{l}1 \text { if PIP } 0 \text { if no } \\
\text { PIP }\end{array}$ \\
\hline $\begin{array}{l}\text { Secondary } \\
\text { exposure } \\
\text { variable }\end{array}$ & $\begin{array}{l}\text { First } \\
\text { criterion-specific PIP } \\
\text { incidence density }\end{array}$ & $\begin{array}{l}\text { Number of instances of first PIP } \\
\text { for each criterion experienced by } \\
\text { a patient during his/her eligibility } \\
\text { period divided by the duration of } \\
\text { the study eligibility period in } \\
\text { years (will be calculated } \\
\text { separately for STOPP/START } \\
\text { and Beers' criteria). }\end{array}$ & Continuous & 0 to unlimited & Counts/year \\
\hline $\begin{array}{l}\text { Primary } \\
\text { outcome } \\
\text { variable }\end{array}$ & $\begin{array}{l}\text { Time to any } \\
\text { outcome }\end{array}$ & $\begin{array}{l}\text { Time between first PIP and first } \\
\text { of ER visit, hospitalisation or } \\
\text { death, occurring within the time } \\
\text { window for 'PIP relevant } \\
\text { outcomes' (usually up to } \\
3 \text { months after an instance of } \\
\text { PIP, but may be longer for some } \\
\text { criteria-see text for examples) }\end{array}$ & Ordinal & $0-90$ & Days \\
\hline $\begin{array}{l}\text { Secondary } \\
\text { outcome }\end{array}$ & Time to ER visit & $\begin{array}{l}\text { Time between first PIP and first } \\
\text { ER visit }\end{array}$ & Ordinal & $0-90$ & Days \\
\hline \multirow[t]{2}{*}{ variables } & $\begin{array}{l}\text { Time to } \\
\text { hospitalisation }\end{array}$ & $\begin{array}{l}\text { Time between first PIP and first } \\
\text { hospitalisation }\end{array}$ & Ordinal & $0-90$ & Days \\
\hline & Time to ADE & $\begin{array}{l}\text { Time to any diagnostic code for } \\
\text { an ADE }\end{array}$ & Ordinal & 0-90 & Days \\
\hline \multirow[t]{10}{*}{ Covariates } & Patient age & Patient's age at time of first PIP & Continuous & $66-116$ & Years \\
\hline & Patient sex & Patient's biological gender & Dichotomous & Male or female & Male or female \\
\hline & Patient location & $\begin{array}{l}\text { Type of setting a patient lives in } \\
\text { at time of PIP }\end{array}$ & Dichotomous & $\begin{array}{l}\text { Long-term care vs } \\
\text { community setting }\end{array}$ & $\begin{array}{l}\text { Long-term care } \\
\text { vs community } \\
\text { setting }\end{array}$ \\
\hline & $\begin{array}{l}\text { Number of } \\
\text { prescribers }\end{array}$ & $\begin{array}{l}\text { Number of prescribers who have } \\
\text { issued prescriptions for a patient } \\
\text { in year prior to the first PIP }\end{array}$ & Continuous & 1 to unlimited & Count \\
\hline & $\begin{array}{l}\text { Number of } \\
\text { dispensing } \\
\text { pharmacists }\end{array}$ & $\begin{array}{l}\text { Number of pharmacists from } \\
\text { whom a patient obtained } \\
\text { medication in the year prior to the } \\
\text { first PIP }\end{array}$ & Continuous & 1 to unlimited & Count \\
\hline & Polypharmacy & $\begin{array}{l}\text { Number of medications } \\
\text { concurrently in use at time of } \\
\text { prescription of a PIP }\end{array}$ & Continuous & 1 to unlimited & Count \\
\hline & SES & $\begin{array}{l}\text { Socioeconomic quintile attributed } \\
\text { to patient on the basis of his/her } \\
\text { census data and postal code }\end{array}$ & Ordinal & $\begin{array}{l}\text { Very low SES, low } \\
\text { SES, middle SES, } \\
\text { high SES, very } \\
\text { high SES }\end{array}$ & Quintile \\
\hline & Prior hospitalisations & $\begin{array}{l}\text { Number of hospital admissions } \\
\text { experienced by a patient in the } \\
12 \text { months preceding a PIP }\end{array}$ & Continuous & 0 to unlimited & Count \\
\hline & $\begin{array}{l}\text { ER visit in past } \\
6 \text { months }\end{array}$ & $\begin{array}{l}\text { Number of visits made to the } \\
\text { emergency room by a patient in } \\
\text { the } 6 \text { months preceding a PIP }\end{array}$ & Continuous & 0 to unlimited & Count \\
\hline & Comorbidities & $\begin{array}{l}\text { Deyo modification of Charlson } \\
\text { Comorbidity Index for a patient } \\
\text { calculated at the time of first PIP, } \\
\text { if patient was hospitalised in the } \\
\text { year prior to the first PIP; for } \\
\text { patients who were not } \\
\text { hospitalised, we will use the } \\
\text { Johns Hopkins ADG score }\end{array}$ & Continuous & $0-32$ & NA \\
\hline
\end{tabular}


Table 1 Continued

\begin{tabular}{|c|c|c|c|c|c|}
\hline Category & Variable name & Definition & Scale & Valid range/levels & Units \\
\hline & $\begin{array}{l}\text { Acuity of prior } \\
\text { hospitalisations }\end{array}$ & $\begin{array}{l}\text { Whether a hospitalisation } \\
\text { occurring in the } 12 \text { months } \\
\text { preceding a PIP was coded as } \\
\text { 'acute' or not in the Discharge } \\
\text { Abstract Database }\end{array}$ & Dichotomous & Acute vs other & $\begin{array}{l}1 \text { if acute } 0 \text { if } \\
\text { other }\end{array}$ \\
\hline & Discharge diagnosis & $\begin{array}{l}\text { Most responsible diagnosis for a } \\
\text { hospitalisation occurring in the } \\
12 \text { months preceding a PIP as } \\
\text { recorded in the Discharge } \\
\text { Abstract Database }\end{array}$ & Categorical & ICD groups & $\begin{array}{l}\text { Diagnostic } \\
\text { groups }\end{array}$ \\
\hline & $\begin{array}{l}\text { Prescribing } \\
\text { physician age }\end{array}$ & Physician age & Continuous & 20 to ?? & years \\
\hline & $\begin{array}{l}\text { Prescribing } \\
\text { physician sex }\end{array}$ & Physician's biological gender & Dichotomous & Male or female & Male or female \\
\hline & $\begin{array}{l}\text { Prescribing } \\
\text { physician year of } \\
\text { graduation }\end{array}$ & Physician year of graduation & Ordinal & 1945 to ?? & Year (date) \\
\hline & $\begin{array}{l}\text { Prescribing } \\
\text { physician location }\end{array}$ & $\begin{array}{l}\text { Physician location of practice } \\
\text { (rural vs urban) }\end{array}$ & Dichotomous & Rural vs urban & 0 rural, 1 urban \\
\hline & $\begin{array}{l}\text { Type of prescribing } \\
\text { physician }\end{array}$ & $\begin{array}{l}\text { Type of physician prescribing a } \\
\text { PIP for a given patient }\end{array}$ & Dichotomous & $\begin{array}{l}\text { Specialist vs family } \\
\text { physician }\end{array}$ & $\begin{array}{l}\text { Specialist or } \\
\text { family MD }\end{array}$ \\
\hline
\end{tabular}

ICES-derived cohorts as appropriate. Three members of our team (a pharmacist (RH), a physician/epidemiologist (LMB) and a data analyst (ChC)) will identify this subset of criteria using an iterative process. They will assess the updated 2014 STOPP/START and 2012 Beers' criteria for applicability to Ontario/ICES health administrative data, codify them using appropriate diagnostic (ICD-International Classification of Disease) and medication (DIN) codes, and convert them to SAS code for use with ICES data. The resultant criterion selection and coding will be reviewed by all co-authors and approved by an iterative discussion and consensus process.

\section{Primary outcome}

Because ADEs are frequently under-recognised during ED visits and hospitalisations, ${ }^{36}{ }^{37}$ our study cohort is also subject to substantial underestimation of ADEs. We have therefore chosen to focus on reliably documented clinical events, namely ED visits, hospitalisation and death as our main outcome events, even though we recognise that not all will be causally related to a PIP. We will control for this using multivariate methods. The primary study end point is the time from the first PIP ever (during the accrual period) for any STOPP/START or Beers' criterion to the first PIP-related event, which is defined as the first all-cause ED visit, hospitalisation or death occurring within 3 months after this PIP.

In secondary analyses, we will look at time to outcomes following first PIPs for individual criteria, which means that patients can have more than one PIP-related event (one for each criterion they fulfil; see figure 3). Each type of PIP-related event (ie, ED visits, hospitalisations and deaths) will also be considered as a separate outcome and ADEs-related outcomes will be identified using diagnostic codes. ED visits will be determined from the NACRS database, hospitalisations from the DAD database and death will be determined from the RPDB. The relationship between these events and time intervals is illustrated in figure 3 , together with a few examples of possible patient scenarios.

If the PIP includes a time-dependent definition (eg, 'NSAID use $>3$ months'), the observation window will be extended by 3 months beyond the specified minimum exposure (thus, the outcome observation window would be 6 months in the above example).

\section{Censoring}

Patients will be censored if they die or move out of the province without experiencing an event, and their move is captured by the RPDB. For the observation window following an instance of PIP, we have chosen a 3-month cut-off since we anticipate that the potential influence of an instance of PIP would not likely last longer than this, and probably would be shorter. If a patient experiences an event other than death (ie, an ED visit or hospitalisation), that patient will be censored for the duration of that event, but will remain in the study cohort after discharge from the ED or hospital, as he/she may contribute further instances of PIP to the study base.

\section{Covariates}

Our analyses will control for the following covariates, which are either known or perceived to be associated with PIP and subject to their availability in the provincial 

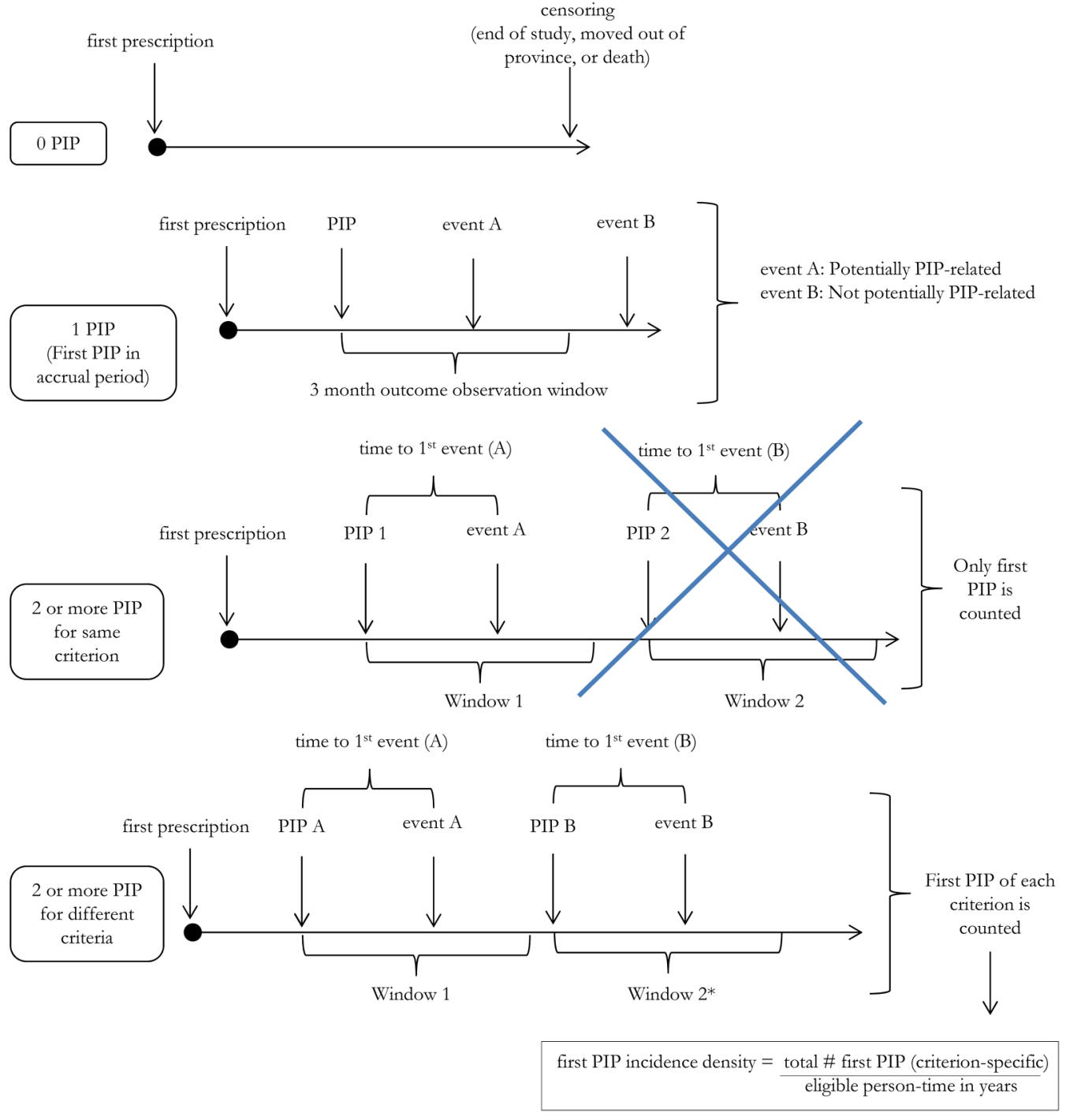

- PIP: potentially inappropriate prescribing

- Event: Emergency Department (ED) visit, hospitalization, or death

- Censoring: If event is ED visit or hospitalization, the patient remains in study after discharge back to the community to enable inclusion of patients with multiple PIPs from different criteria

* If the observation time windows overlap, the event is attributed to the most recent PIP

Figure 3 Time-to-event as a function of potentially inappropriate prescribing (PIP): possible patient scenarios, definition of eligible exposure and of outcome observation time window.

health administrative databases (table 1 for a full list of variable definitions): patient age, prescribing physician sex, type of physician (specialist vs family physician), physician year of graduation, practice location (urban vs rural), whether a patient has a regular family physician, number of prescribers in the year prior to a PIP, ${ }^{13}$ number of dispensing pharmacists during study eligibility period, patient location (long-term care vs community setting) ${ }^{16}$ and polypharmacy (number of drugs used concurrently by one patient at the time of prescription of a PIP).$^{38-42}$ Other patient-level factors known or suspected of being associated with unplanned hospital admissions and ED visits will also be included in the analyses as covariates: age,$^{43}{ }^{44} \mathrm{sex}^{44}$ socioeconomic status (SES), ${ }^{44} 45$ rurality, comorbidity ${ }^{44} 4647$ (calculated using the Deyo modification ${ }^{48}$ of the Charlson's Comorbidity Index $\left.(\mathrm{CCI})^{49}\right)$, Johns Hopkins Adjusted Clinical Groups (ACG) system, ${ }^{50}$ number of ED visits in 6 months prior to a PIP, number of prior hospitalisations in the 12 months preceding a PIP, ${ }^{43} 4^{46}{ }^{51-55}$ and whether a patient has had a MedsCheck or Pharmaceutical Opinion assessment performed in year prior to first PIP. We will use the postal code conversion file to link the patient's postal code to the dissemination area, which is the smallest geographical census unit that exists across all of Canada. We will then use census data to determine the median household income of each dissemination area, which we will use as a proxy for individual SES. Linear interpolation will be used to infer income for non-census years. 


\section{Statistical analyses}

In order to address each of our three hypotheses, we will fit multivariable regression models. We will retain all of the prespecified covariates in the model regardless of statistical significance, and we will validate our fitted models using modern bootstrap validation methods to assess predictive performance and protect against overfitting. ${ }^{56}$

The 'skeleton' tables of expected results for each of the three hypotheses are shown in online supplementary appendices A-C, respectively. In accordance with standard ICES procedures, data cell sizes containing fewer than five counts will not be reported to protect confidentiality.

Hypothesis 1: Instances of PIP are frequent and costly.

We will describe the characteristics of the study cohort using the parameters described in online supplementary table 1A. To test hypothesis 1 , we will first apply the STOPP/START and Beers' criteria subset (as defined in the 'Exposure variable' section above) to our data by identifying the occurrence of the first PIP ever, and also, in secondary analyses, by calculating the first criterionspecific PIP incidence density (see online supplementary table 1B), and make comparisons to other studies that used STOPP/START and Beers. Subgroup analyses will be conducted to estimate PIP incidence density in long-term care and ambulatory patients (see online supplementary table 1B), as these individuals are particularly vulnerable to PIP. ${ }^{57}$

We will estimate the annual attributable risk $^{58}$ of adverse events by grouping patients' first PIP incidence density (no PIP (reference), $\leq 1 \mathrm{PIP} /$ year, $1 \leq 2 \mathrm{PIP} /$ year, $2 \leq 3 \mathrm{PIP} /$ year, $2 \leq 3 \mathrm{PIP} /$ year), and calculate HRs for each group (see online supplementary table 1C). Patients who did not experience a PIP will serve as the reference category. We will apply the HRs for each group to the proportion of the population attributable to that group, using the frequency of events in the reference category as a baseline. This will yield an estimate of the frequency of adverse events attributable to PIP, a quantity that can also be expressed as an annual number of adverse potential PIP-related events experienced by Ontario seniors. We will conduct this calculation using all primary and secondary outcomes.

To estimate the overall cost of PIPs, we will combine direct medication-related and direct non-medication (healthcare utilisation)-related costs (see online supplementary table 1D). Medication-related costs will be calculated by aggregating all medications costs (including medication costs and dispensing fees) associated with each PIP in the study cohort. In instances where a PIP involves more than one drug, only the cost of the cheaper drug will be included, yielding a conservative estimate; if a PIP involves the use of a high-dose drug (with low-dose not considered a PIP), then we will consider only the difference in price between high and low dose as a potential saving. Healthcare utilisation costs (direct non-medication costs) will include the costs of
ED visits and hospitalisations that are attributable to each PIP, as defined above by the attributable risk.

Hypothesis 2: ED visits and hospitalisations are significantly associated with PIP.

To test this hypothesis, we will use two complementary approaches. First, a logistic regression will be performed to assess the association between the occurrence of a first PIP ever and the likelihood of PIP-related events. The reference category for this step will be '0 PIP'. Second, a time-to-event analysis will be carried out to address the following question: among patients experiencing PIP, does the likelihood of a PIP-related events depend on the total number of first PIPs by criteria occurring before a given event? We will use ' 1 ' as a reference category for this step. We will control for covariates known or suspected of being associated with PIP (see Covariates section above) by including them in our models. Additional analyses that may be conducted, if applicable (tables not shown): instrumental variables regressions to adjust for potential unmeasured confounders, hierarchical models to address clustering, and sensitivity analyses with different suboutcomes (time to ED visit, time to hospitalisation, time to death, time to $\mathrm{ADE})$.

Hypothesis 3: The likelihood of inappropriate prescribing is associated with patient and physician characteristics.

To test this hypothesis, we will identify each physician's PIP incidence density, calculated by dividing the number of first PIP per patient they issued by the total number of first prescriptions they provided over the study period and then use a multilevel model to explore the association of patient-level and physician-level covariates with incidents. We will use intracluster correlation coefficients to estimate the variation in PIP prescribing across prescribers and to identify which covariates may explain this variation (see online supplementary table $3 \mathrm{~A}){ }^{59}$

Next, we will perform a multivariate linear regression to describe provider and patient characteristics associated with first PIP incidence density (see online supplementary table 3B), which will be ranked and categorised into deciles and will act as the dependent variable, with prescriber and patient characteristics serving as independent variables. We expect to find that certain patient characteristics (eg, age, number of prescribers) and prescriber characteristics (eg, rurality, sex, age) are significantly associated with PIP density, as identified in previous studies. ${ }^{13}$

Finally, we will describe the distribution of first PIP incidence density and then use a multilevel model to explore the association of patient-level and physicianlevel covariates and patient outcomes (ED visits, hospitalisations and mortality).

\section{Cohort size and power}

Dispensation of a first prescription represents a patient's point of entry into our study population. Every year in 
Ontario, over 50 million prescriptions are dispensed and recorded in the ODBD. ${ }^{35}$ The Ontario population in 2006 (mid-way through our study period) was approximately $12600000,{ }^{60}$ of which about $14 \%$ were seniors, ${ }^{2}$ corresponding to 1680000 seniors. Given that this is a dynamic population, with additions through ageing of the population and patients moving into the province, and losses through deaths and emigration, the actual number of seniors in the database can be expected to be higher, around 2-2.5 million patients. Given an average annual number of medications per senior of $6.7,{ }^{2}$ this would translate into approximately 13 million medications being prescribed under ODB per year (with more prescriptions, since there may be more than one prescription for the same medication). Given our 10-year accrual period (1 April 2003 to 31 March 2013), we could expect to have access to a total of over 130 million different instances of medications dispensed to individual patients, and even more prescriptions.

As for event rates, applying a rate of PIP of $22 \%$ in primary care found in earlier studies ${ }^{16}$ would result in about 500000 elderly patients experiencing PIPs per year in Ontario (based on an estimated seniors population of about 1.6 million). Since some patients will experience more than one type of PIP during the study accrual period, the number of eligible observations will be greater.

This large cohort size, in terms of patients, number of prescriptions and PIPs, ensures high statistical power to detect any effect of even minor clinical importance. However, we are in fact conducting a census of all eligible patients-as opposed to sampling a populationrendering a power calculation of little value. Nonetheless, even if this represented a population sample, we would have more than $90 \%$ power for the vast majority of our planned analyses.

\section{ETHICS AND DISSEMINATION Registration}

This cohort study is registered with clinicaltrials.gov (registration number: NCT02555891)

\section{Dissemination}

Dissemination will occur via publication, presentations at national and international conferences, professional networks, and ongoing exchanges with regional, provincial and national stakeholders, including the Ontario Drug Policy Research Network and the Ontario MOHLTC.

\section{Statement of originality}

To the best of our knowledge, the association of PIP with patient outcomes, prescriber characteristics and healthcare utilisation has not been studied in such a large population-based study in any jurisdiction. Ontario's extensive holdings of linked health administrative databases provide a unique opportunity to examine the effects of PIP on a large scale.

\section{Anticipated limitations}

Our study is subject to several limitations inherent in studies relying on health administrative data. We cannot guarantee that patients regularly took the medications dispensed to them, or that they adhered to the guidelines for their use. Adherence to treatment can only be assessed by comparing the date when an original prescription was scheduled to expire with the dispensation date of the renewal prescription. Some over-the-counter medications included in the STOPP criteria subset (eg, low-dose acetylsalicylic acid (ASA)) as well as medication not covered by ODB plan (eg, sildenafil-Viagra) are not recorded in the ODBD and thus cannot be included. It is also possible that some PIP identified by the STOPP criteria subset in our database would actually be considered appropriate were clinical or diagnostic data available to support their use. ${ }^{61}$ That said, we anticipate that some laboratory values housed in Ontario's Laboratory Integration System (OLIS) will become available to researchers using ICES data within the coming year or two. We expect that this will enable us to expand the subset of STOPP/START and Beers' criteria applicable to health administrative data. ${ }^{62}$ Despite these limitations, we are confident that our study will produce useful estimates of the occurrence of PIP in Ontario's senior population, enable us to assess the health outcomes and health system costs associated with PIP, and help evaluate an existing measure aimed at mitigating its effects.

\section{Safety and confidentiality considerations}

Our study will make use of previously collected data, and will not require any additional intervention or data collection at the patient level. This study will be conducted using Ontario health administrative databases housed at the ICES, accessed from the ICES@uOttawa site. ICES is an independent, non-profit organisation whose infrastructure funding and access to Ontario's large administrative databases is provided by the Ontario MOHLTC. ICES links de-identified population-based health information at the patient level in a way that ensures privacy and confidentiality of patients. ICES is named as a section 45(1) Prescribed Entity in Ontario's Personal Health Information Protection Act (PHIPA). Review, audit and approval of ICES' policies, practices and procedures related to data privacy and security are performed triannually by the Information and Privacy Commissioner of Ontario (IPC). This approval/review document is available at http://www.ipc.on.ca. All of these data sets are linked using a patient-specific encrypted identifier. This linkage is deterministic and does not require any probabilistic methods. As per usual ICES procedures, cell sizes $<5$ will not be reported to address concerns about possible breaches in confidentiality.

Author affiliations

${ }^{1}$ Department of Family Medicine, University of Ottawa, Ottawa, Ontario, Canada 
${ }^{2}$ Bruyère Research Institute, Ottawa, Ontario, Canada

3ICES@ uOttawa, Ottawa, Ontario, Canada

${ }^{4}$ School of Epidemiology, Public Health and Preventive Medicine, University of Ottawa, Ottawa, Ontario, Canada

${ }^{5}$ Ottawa Hospital Research Institute, Ottawa, Ontario, Canada

${ }^{6}$ Economic and Social Research Institute, Trinity College Dublin, Dublin, Ireland

${ }^{7}$ School of Pharmacy, Royal College of Surgeons in Ireland, Dublin, Ireland

${ }^{8}$ School of Pharmacy, University of Waterloo, Waterloo, Ontario, Canada

${ }^{9}$ School of Pharmacy, University of Uppsala, Uppsala, Sweden

Acknowledgements The authors thank Justin Joshcko for helpful editorial suggestions, as well as Matt Hogel and Chandra Landry for proofreading and editorial suggestions at various stages in the creation of this manuscript; they also thank Chandra Landry and Cody Black for invaluable help with formatting references, tables and figures.

Contributors LMB conceived of the idea for this project, wrote the original grant application (see online supplementary appendix E), updated and adapted it to fit the requirements of the present protocol; she also generated all the tables in the present manuscript, as well as in the online supplementary material appendices. TR, CaC, $\mathrm{CR}, \mathrm{RH}, \mathrm{BF}, \mathrm{KT}, \mathrm{ChC}, \mathrm{SH}, \mathrm{UG}$ and DGM provided expertise in their respective fields, all reviewed the manuscript for important intellectual content and made suggestions for improvement as appropriate; furthermore, they all approved the final version of the manuscript for submission.

Funding This work was supported by the Canadian Institutes of Health Research (CHIR), grant number 287245-HPM-BRUY-46830.

Competing interests $\mathrm{CaC}$ is the author of the study that applied a subset of the 2008 STOPP criteria to an Irish prescription database. ${ }^{9} \mathrm{CR}$ is a co-author of the original STOPP/START criteria. $^{20} 21$

Competing interests None declared.

Ethics approval Ottawa Health Services Network Ethical Review Board and BruyereBruyère Research Institute Ethics Review Board (see online supplementary appendix D).

Provenance and peer review Not commissioned; peer reviewed for ethical and funding approval prior to submission.

Open Access This is an Open Access article distributed in accordance with the Creative Commons Attribution Non Commercial (CC BY-NC 4.0) license, which permits others to distribute, remix, adapt, build upon this work noncommercially, and license their derivative works on different terms, provided the original work is properly cited and the use is non-commercial. See: http:// creativecommons.org/licenses/by-nc/4.0/

\section{REFERENCES}

1. Canadian Institute for Health Information. Drug use among seniors on public drug programs in Canada, 2012. Ottawa, Ontario, 2014.

2. Canadian Institute for Health Information (CIHI). Drug use among seniors on public drug programs in Canada, 2002 to 2008. Ottawa, Ontario: ClHI, 2010.

3. Merle L, Laroche M-L, Dantoine T, et al. Predicting and preventing adverse drug reactions in the very old. Drugs Aging 2005;22:375-92.

4. Hutchison LC, O'Brien CE. Changes in pharmacokinetics and pharmacodynamics in the elderly patient. $J$ Pharm Pract 2007;20:4-12

5. Laroche ML, Charmes JP, Nouaille $\mathrm{Y}$, et al. Is inappropriate medication use a major cause of adverse drug reactions in the elderly? Br J Clin Pharmacol 2007;63:177-86.

6. Wu C, Bell C, Wodchis W. Incidence and economic burden of adverse drug reactions among elderly patients in Ontario emergency departments: a retrospective study. Drug Saf 2012;35:769-81.

7. Lazarou J, Pomeranz BH, Corey PN. Incidence of adverse drug reactions in hospitalized patients: a meta-analysis of prospective studies. JAMA 1998;279:1200-5.

8. Hamilton $\mathrm{H}$, Gallagher P, Ryan C, et al. Potentially inappropriate medication defined by STOPP criteria and the risk of adverse drug events in older hospitalized patients. Arch Intern Med 2011;171:1013-19.
9. Cahir C, Fahey T, Teeling M, et al. Potentially inappropriate prescribing and cost outcomes for older people: a national population study. Br J Clin Pharmacol 2010;69:543-52.

10. Goltz L, Kullak-Ublick GA, Kirch W. Potentially inappropriate prescribing for elderly outpatients in Germany: a retrospective claims data analysis. Int J Clin Pharmacol Ther 2012;50:185.

11. Shah RB, Gajjar BM, Desai SV. Evaluation of the appropriateness of prescribing in geriatric patients using Beers criteria and Phadke's criteria and comparison thereof. J Pharmacol Pharmacother 2011;2:248-52.

12. Byrne S, Ryan C, O'Mahony D, et al. Inappropriate prescribing in the elderly: a review of primary care and nursing home prescriptions. Int J Pharm Pr 2008;16(Suppl 1):A36-7.

13. Dhalla IA, Anderson GM, Mamdani MM, et al. Inappropriate prescribing before and after nursing home admission. J Am Geriatr Soc 2002;50:995-1000.

14. Dimitrow MS, Airaksinen MS, Kivelä SL, et al. Comparison of prescribing criteria to evaluate the appropriateness of drug treatment in individuals aged 65 and older: a systematic review. J Am Geriatr Soc 2011; 59:1521-30.

15. Fick DM, Cooper JW, Wade WE, et al. Updating the Beers criteria for potentially inappropriate medication use in older adults: results of a US consensus panel of experts. Arch Intern Med 2003:163:2716.

16. O'Mahony D, Gallagher P, Ryan C, et al. STOPP \& START criteria: a new approach to detecting potentially inappropriate prescribing in old age. Eur Geriatr Med 2010;1:45-51.

17. Page RL, Linnebur SA, Bryant LL, et al. Inappropriate prescribing in the hospitalized elderly patient: defining the problem, evaluation tools, and possible solutions. Clin Interv Aging 2010;5:75-87.

18. Ryan C, O'Mahony D, Kennedy J, et al. Appropriate prescribing in the elderly: an investigation of two screening tools, Beers criteria considering diagnosis and independent of diagnosis and improved prescribing in the elderly tool to identify inappropriate use of medicines in the elderly in primary care in Ireland. $J$ Clin Pharm Ther 2009;34:369-76.

19. Patterson S, Hughes C, Kerse N, et al. Interventions to improve the appropriate use of polypharmacy for older people. Cochrane Database Syst Rev 2012;5:CD008165.

20. Gallagher P, O'Mahony D. STOPP (Screening Tool of Older Persons' potentially inappropriate Prescriptions): application to acutely ill elderly patients and comparison with Beers' criteria. Age Ageing 2008;37:673-9.

21. O'Mahony D, O'Sullivan D, Byrne S, et al. STOPP/START criteria for potentially inappropriate prescribing in older people: version 2 Age Ageing 2014;16:1-6.

22. Ryan C, O'Mahony D, Kennedy J, et al. Potentially inappropriate prescribing in an Irish elderly population in primary care. $\mathrm{Br} \mathrm{J}$ Clin Pharmacol 2009;68:936-47.

23. Gallagher PF, O'Connor MN, O'Mahony D. Prevention of potentially inappropriate prescribing for elderly patients: a randomized controlled trial using STOPP/START criteria. Clin Pharmacol Ther 2011;89:845-54.

24. Beers MH, Ouslander JG, Rollingher I, et al. Explicit criteria for determining inappropriate medication use in nursing home residents. Arch Intern Med 1991;151:1825.

25. Beers $\mathrm{MH}$. Explicit criteria for determining potentially inappropriate medication use by the elderly: an update. Arch Intern Med 1997;157:1531-6.

26. American Geriatrics Society 2012 Beers Criteria Update Expert Panel. American Geriatrics Society updated Beers Criteria for potentially inappropriate medication use in older adults. J Am Geriatr Soc 2012;60:616-31.

27. Marcum ZA, Hanlon JT. Commentary on the New American Geriatric Society Beers Criteria for potentially inappropriate medication use in older adults. Am J Geriatr Pharmacother 2012;10:151

28. Resnick B, Pacala JT. 2012 Beers Criteria. J Am Geriatr Soc 2012;60:612-13.

29. Fick DM, Semla TP. 2012 American Geriatrics Society Beers Criteria: new year, new criteria, new perspective. J Am Geriatr Soc 2012;60:614-15.

30. Page RL, Ruscin JM. The risk of adverse drug events and hospital-related morbidity and mortality among older adults with potentially inappropriate medication use. Am J Geriatr Pharmacother 2006;4:297-305.

31. Levy H, Marcus E, Christen C. Beyond the beers criteria: a comparative overview of explicit criteria. Ann Pharmacother 2010;44:1968-75

32. Gracía-Gollarte F, Júlvez J, Ferrero-López I, et al. An educational intervention on drug use in nursing homes improves health outcomes resource utilization and reduces inappropriate drug prescription. J Am Med Dir Assoc 2014;15:885-91. 
33. Frankenthal D, Lerman $\mathrm{Y}$, Kalendaryev $\mathrm{E}$. Intervention with the screening tool of older persons potentially inappropriate prescriptions/screening tool to alert doctors to right treatment criteria in elderly residents of a chronic geriatric facility: a randomized clinical trial. J Am Geriatr Soc 2014;62:1658-65.

34. Bronskill S, Carter M, Costa A, et al. Aging in Ontario: an ICES chartbook of health service use by older adults-technical report. Toronto, 2010.

35. Institute for Clinical Evaluative Sciences (ICES). Health services data. 2011. http://www.ices.on.ca/webpage.cfm?site_id=1\&org_ id=26\&morg_id=0\&gsec_id=5314\&item_id=5326

36. Hohl C, Zed $\mathrm{P}$, Brubacher J, et al. Do emergency physicians attribute drug-related emergency department visits to medicationrelated problems? Ann Emerg Med 2010;55:493-502.

37. Hohl C, Robitaille C, Lord V, et al. Emergency physician recognition of adverse drug-related events in elder patients presenting to an emergency department. Acad Emerg Med 2005;12 197-205.

38. Hajjar ER, Cafiero AC, Hanlon JT. Polypharmacy in elderly patients. Am J Geriatr Pharmacother 2007;5:345-51.

39. Bates DW, Miller EB, Cullen DJ, et al. Patient risk factors for adverse drug events in hospitalized patients. ADE Prevention Study Group. Arch Intern Med 1999;159:2553-60.

40. Carey IM, De WS, Harris T, et al. What factors predict potentially inappropriate primary care prescribing in older people? Analysis of UK primary care patient record database. Drugs Aging 2008;25:693-706.

41. Evans RS, Lloyd JF, Stoddard GJ, et al. Risk factors for adverse drug events: a 10-year analysis. Ann Pharmacother 2005;39:1161-8.

42. Kanjanarat $P$, Winterstein $A G$, Johns TE, et al. Nature of preventable adverse drug events in hospitals: a literature review. Am J Heal Syst Pharm 2003;60:1750-9.

43. Boult C, Dowd B, McCaffrey D, et al. Screening elders for risk of hospital admission. J Am Geriatr Soc 1993;41:811-17.

44. Anderson GF, Steinberg EP. Predicting hospital readmissions in the Medicare population. Inquiry 1985;22:251-8.

45. Weissman J, Stern R, Epstein A. The impact of patient socioeconomic status and other social factors on readmission: a prospective study in four Massachusetts hospitals. Inquiry 1994;31:163-72.

46. Krumholz HM, Parent EM, Tu N, et al. Readmission after hospitalization for congestive heart failure among Medicare beneficiaries. Arch Intern Med 1997;157:99-104.
47. Chin $\mathrm{MH}$, Goldman L. Correlates of early hospital readmission or death in patients with congestive heart failure. Am J Cardiol 1997;79:1640-4.

48. Deyo RA, Cherkin DC, Ciol MA. Adapting a clinical comorbidity index for use with ICD-9-CM administrative databases. J Clin Epidemiol 1992;45:613-19.

49. Charlson ME, Pompei $\mathrm{P}$, Ales KL, et al. A new method of classifying prognostic comorbidity in longitudinal studies: development and validation. J Chronic Dis 1987;40:373-83.

50. Austin PC, van Walraven C, Wodchis WP, et al. Using the Johns Hopkins Aggregated Diagnosis Groups (ADGs) to predict mortality in a general adult population cohort in Ontario, Canada. Med Care 2011;49:932-9.

51. Phillips RS, Safran C, Cleary PD, et al. Predicting emergency readmissions for patients discharged from the medical service of a teaching hospital. J Gen Intern Med 1987;2:400-5.

52. Reed RL, Pearlman RA, Buchner DM. Risk factors for early unplanned hospital readmission in the elderly. J Gen Intern Med 1991;6:223-8.

53. Corrigan JM, Martin JB. Identification of factors associated with hospital readmission and development of a predictive model. Health Serv Res 1992;27:81-101.

54. Colledge NR, Ford MJ. The early hospital readmission of elderly people. Scott Med J 1994;39:51-2.

55. van Walraven C, Mamdani M, Fang J, et al. Continuity of care and patient outcomes after hospital discharge. J Gen Intern Med 2004;19:624-31.

56. Harrell F. Regression modeling strategies. 2nd edn. Springer International Publishing, 2015.

57. Bronskill S, Gill S, Paterson J, et al. Exploring variation in rates of polypharmacy across long term care homes. J Am Med Dir Assoc 2012;13:309.e15-21.

58. Armitage G, Berry P. Statistical methods in medical research Oxford: Blackwell Scientific Publishing, 1994.

59. Guthrie B, McCowan C, Davey $\mathrm{P}$, et al. High risk prescribing in primary care patients particularly vulnerable to adverse drug events: cross sectional population database analysis in Scottish general practice. BMJ 2011;342:d3514.

60. Canada S. 2006 Census highlights: factsheet 1. 2009. http://www. fin.gov.on.ca/en/economy/demographics/census/cenhi06-1.html

61. Ryan C, O'Mahony D, O'Donovan DÓ, et al. A comparison of the application of STOPP/START to patients' drug lists with and without clinical information. Int J Clin Pharm 2013;35:230-5.

62. Institute for Clinical Evaluative Sciences (ICES). ICES internal communication, April 7 2015. 2015. 